\title{
Fore-Stomach Foreign Bodies: prevalence, associat- ed risk factors and types affecting cattle slaughtered at Gondar ELFORA abattoir, northwest Ethiopia
}

\author{
Amare Bihon ${ }^{1^{*}}$, Teketaye Bayeleyegn ${ }^{1}$, Ayalew Assefa ${ }^{2}$ and Yimer Muktar ${ }^{1}$ \\ ${ }^{1}$ College of Agriculture, Woldia University, Woldia, Ethiopia \\ ${ }^{2}$ Sekota Dryland Agricultural Research Center, Sekota, Ethiopia \\ *Corresponding author: Email: amarevet5@gmail.com: Tel: +251-(0)9-45143238 and ORCID: \\ https://orcid.org/0000-0003-1766-9889
}

\begin{abstract}
In Ethiopia, recurrent drought and feed shortage coupling with high level of environmental pollution predispose the animals to foreign body ingestion. A cross-sectional study with systematic random sampling approach was employed from November 2018 to April, 2019 with the objectives of estimating the prevalence; identify associated risk factors and to categorize the types of foreign body in cattle slaughtered at Gondar ELFORA Abattoir. Ante-mortem and postmortem examinations were used to collect the data. From the total of 384 animals examined, the overall prevalence of foreign body was 83(21.61\%). Adult and old animals were $4.33(95 \% \mathrm{CI}=0.98,19.00, p=0.052)$ and $4.54(95 \%$ $\mathrm{CI}=1.03,19.96, p=0.045)$ times more likely to have a chance of getting foreign body than young animals by keeping another factors constant, respectively. However, the difference is not statistically significant for adult cattle. Moreover, poor and medium body conditioned animals were 2.19 (95\% CI=1.04, 4.56, $p=0.037)$ and $1.51(95 \% \mathrm{CI}=0.72,3.13, p=0.273)$ times more likely to acquire foreign bodies than good body conditioned animals by keeping another factors constant. In the positive cases ( $\mathrm{N}=83), 41(49.40 \%), 34(40.96 \%), 8(9.64 \%)$ and $0(0 \%)$ of the foreign bodies were found in the rumen, reticulum, both rumen and reticulum, and omasum, respectively. Majority of foreign bodies identified (79.51\%) were non-metallic in nature, including clothes, plastics, rope, sand and stone. Designing and implementation of appropriate solid waste disposal and management practices are strongly recommended to reduce the risk of ingestion of indigestible foreign bodies.
\end{abstract}

Keyword: Abattoir; Cattle; Foreign body; Fore stomach; Prevalence 


\section{Introduction}

A lot of documents witnessed huge livestock resource of Ethiopia by describing its priority rank in Africa and $5^{\text {th }}$ in the world (FAO, 2015). According to CSA, (2015) report, the country hosts 56.71 million cattle, 29.33 million sheep and 29.11 million of goats almost all of which are local breed animals. In Ethiopia, like other developing countries, domestic animals contribute in every aspect of household's survival (Kassahu and Wale, 2017). Among domestic animals, cattle take the leading advantage, but still, its contribution is below its expected potential due to different hindering factors like disease (Jemberu et al., 2018). Disease, by its nature, could be infectious and non-infectious in origin (Radostits, 2007). Gastrointestinal foreign bodies are among non-infectious diseases and one of surgical emergencies in veterinary medicine. Cattle are the most susceptible species because of its indiscriminate feeding habit (Tesfaye and Chanie, 2012).

Recurrent drought and feed shortage in Ethiopia coupling with high level of environmental pollution predisposes animals for foreign body ingestion (Tesfaye et al., 2012). Nature and way of entrance of foreign bodies to tissues determine the level and type of complication from glossitis to traumatic reticuloperitonitis (TRP). The ingested foreign bodies may be metallic or non-metallic objects. Metallic foreign bodies mostly reside in the reticulum and may cause perforation of the reticulum resulting in peritonitis, pericarditis or both (Radostitis, 2007) while non-metallic objects may cause ruminal impaction, which hampers the absorption of volatile fatty acids and reduces the level of animal fattening (Vanitha et al., 2010). Foreign body ingestion also called hardware disease and can be diagnosed by ultrasonography, radiology, wither pinch test and rumenotomy. Rumenotomy is both diagnostic and treatment method (Sharma and Pankaj, 2006).

According to Ramaswamy et al, (2011), the presence of extensive construction sites and improper waste disposal can cause the death of beef and dairy cattle due to foreign body ingestion that resulting in a huge economic loss. However, the problem is left unnoticed while it is life threatening and economically devastating. Moreover, its diagnosis, treatment and control in live animals are costly and difficult. Thus, it can be adequately studied in abattoirs. Therefore, the objectives of the present study were assessing the prevalence, identifying risk factors and types of fore-stomach foreign bodies in cattle slaughtered at Gondar ELFORA Abattoir. 


\section{Materials and methods}

\section{Study Area}

The study was conducted at Gondar ELFORA Abattoir, North Gondar zone, Amhara National Regional State. Gondar town is located at $750 \mathrm{Km}$ from Addis Ababa at an elevation of $2200 \mathrm{~m}$ above sea level. The city situated between a latitude and longitude of $12^{\circ} 36^{\prime} \mathrm{N}$ and $33^{\circ} 28^{\prime} \mathrm{E}$. Rain fall varies from $880-1172 \mathrm{~mm}$ with the average annual temperature of $19.7^{\circ} \mathrm{C}$. The abattoir has the capacity of slaughtering up to 250 animals per day. Its daily service ranges from 6-10 animals per day during Christian fasting season and the maximum up to 150 in Christian holydays. Generally, it serves Gondar university student's café which presented 6-10 animals per day except Tuesday and Thursday and some other customers in the town. The university's agent has focal points in Chilga, Metema, Fogera, Debretabor and Gondar town, so the animals are mainly presented from these areas.

\section{Study Animals}

Three hundred eighty four (384) apparently healthy animals presented to Gondar ELFORA abattoir from Gondar town, Debretabour, Fogera, Metema, Chilga and Kolladeba were included in the study. All animals were males and both local and cross breed cattle were included. Age category was done based on dentition eruption described by Pace and Wakeman (2003) as young $(\leq 5$ years), adult (5-10) years) and old ( $\geq 10$ years). Moreover, Body condition of cattle was recorded based on the appearance of the animal and manual palpation of the spinus and transverse processes of the lumbar vertebrae as described by Nicholson and Butterworth (1986) as poor, medium and good body conditions.

\section{Study design and sampling technique}

A cross sectional study with systematic random sampling technique with the inclusion of every $5^{\text {th }}$ animal from the start was included in the sample until the required sample size was fulfilled. Because of the variability of animals presented in the abattoir every day, its service is limited in Christian fasting days (minimum of 6) and higher in the holydays (maximum of 150) from November, 2018 to April, 2019. 


\section{Sample size determination}

Thrusfield (2005) formula was used to calculate the number of animals included in the study. Considering the absence or limitation of previous works, 50\% expected prevalence with $5 \%$ desired level of precision and $95 \%$ of confidence interval, 384 animals were taken.

Where: $\mathrm{n}=$ required sample size, $1.96=$ the value of $\mathrm{Z}$ at $95 \%$ confidence interval Prexp $=$ expected prevalence and $\mathrm{d}=$ desired absolute precision

\section{Data collection method}

Ante mortem examination: This was done according to FAO, (2009) describing a specific range of procedures by considering the behavior, appearance and signs of disease. Animals were examined at rest and in motion during their stay in the lairage for the general status. A unique identification code was given. Then, age, breed and their origin was recorded.

Postmortem examination: palpation, incision and visual inspection were done on Rumen, Reticulum and Omasum immediately after slaughter. Shortly, in the evisceration stages the stomach were carefully removed from the abdominal cavity and incision was given to remove the ingesta and foreign bodies were taken out after visual inspection. Then it was washed with water to remove adhering feed material and to identify types of foreign bodies. When the finding is positive, the location and type of the foreign bodies were recorded and photographed.

\section{Data management and statistical analysis}

The collected data were entered and scored in Microsoft excel worksheet. Before subjected to statistical analysis, the data were thoroughly screened for errors, adequately coded and summarized using descriptive statistics. For analysis, STATA 13 (Stata Corp, TX, USA) was used. Descriptive analysis (frequency and Pearson chi-square (x2) test) and inferential statistics (multiple logistic regressions) were employed to measure the risk caused by associated factors. For all comparisons, P-values less than 0.05 were considered as significant. 


\section{Results}

Risk factors associated with foreign body

The overall prevalence of fore-stomach foreign body was 83(21.61\%) from a total of 384 animals examined. Adult and old animals were 4.33 and 4.54 times more likely to have a chance of getting foreign body than young animals by keeping other factors constant and the association between age groups were significant in old animals $(p<0.05)$. Moreover, poor and medium body conditioned animals were 2.19 and 1.51 times more likely to acquire foreign bodies than good body conditioned animals by keeping other factors constant. The association between body condition is significant among poor and good body conditioned animals $(p>0.05)$ (Table 1$)$

Table 1: Logistic regression analysis of associated risk factors with foreign body

\begin{tabular}{llcccc}
\hline Variable & & $\begin{array}{l}\text { No. } \\
\text { examined }\end{array}$ & Positive (\%) & AOR (95\%CI) & p-value \\
\hline Age & Young & 39 & $2(5.12)$ & Reference & Reference \\
& Adult & 173 & $40(23.12)$ & $4.33(0.98-19.00)$ & 0.052 \\
BCS & Old & 172 & $41(23.84)$ & $4.54(1.03-19.96)$ & 0.045 \\
& Good & 92 & $12(13.04)$ & Reference & Reference \\
& Medium & 163 & $34(20.85)$ & $1.51(0.72-3.13)$ & 0.273 \\
Breed & Loor & 129 & $37(28.68)$ & $2.19(1.04-4.56)$ & 0.037 \\
& Cross & 364 & $75(20.6)$ & Reference & Reference \\
& & 20 & $8(40.0)$ & $2.10(0.78-5.61)$ & 0.140 \\
\hline BSC $=$ Body condition score & & & & Reference \\
& Gondar & 67 & $21(31.34)$ & Reference & 0.090
\end{tabular}




\section{Foreign body location, type and penetration}

From the positive cases (N=83), 41(49.40\%), 34(40.96\%), 8(9.64\%) and $0(0 \%)$ was found in the rumen, reticulum, both rumen and reticulum, and omasum respectively. Regarding types of foreign bodies, 66 (79.51\%), 12(14.46\%), and $5(6.06 \%)$ were non-metal, metal and mixed respectively. Among the positive cases there were $3(3.61 \%)$ cases of penetration on the fore-stomach itself and neighboring organs (Table 2).

Table 2: Foreign body location, type and penetration

\begin{tabular}{llc}
\hline Variable & Category & Frequency (\%) \\
\hline FB location & Rumen & $41(49.40)$ \\
& Reticulum & $34(49.96)$ \\
& Both rumen and reticulum & $8(9.64)$ \\
Type of FB & Omasum & - \\
& Metal & $12(14.46)$ \\
& Non metal & $66(79.51)$ \\
Penetration & Mixed & $5(6.06)$ \\
& Present & $3(3.61)$ \\
Total & Absence & $80(0)$ \\
& & $83(100)$ \\
\hline
\end{tabular}

\section{Distribution of foreign body type due to associated risk factors}

From 384 examined animals, a total of 83 metallic and non-metallic foreign bodies were identified. Non-metallic foreign bodies comprise clothes, plastics, stone, rope and sand whereas, metallic foreign bodies comprise wire, nail, blade and needle. The distribution of foreign body type showed significant difference among breeds (Table 4). 


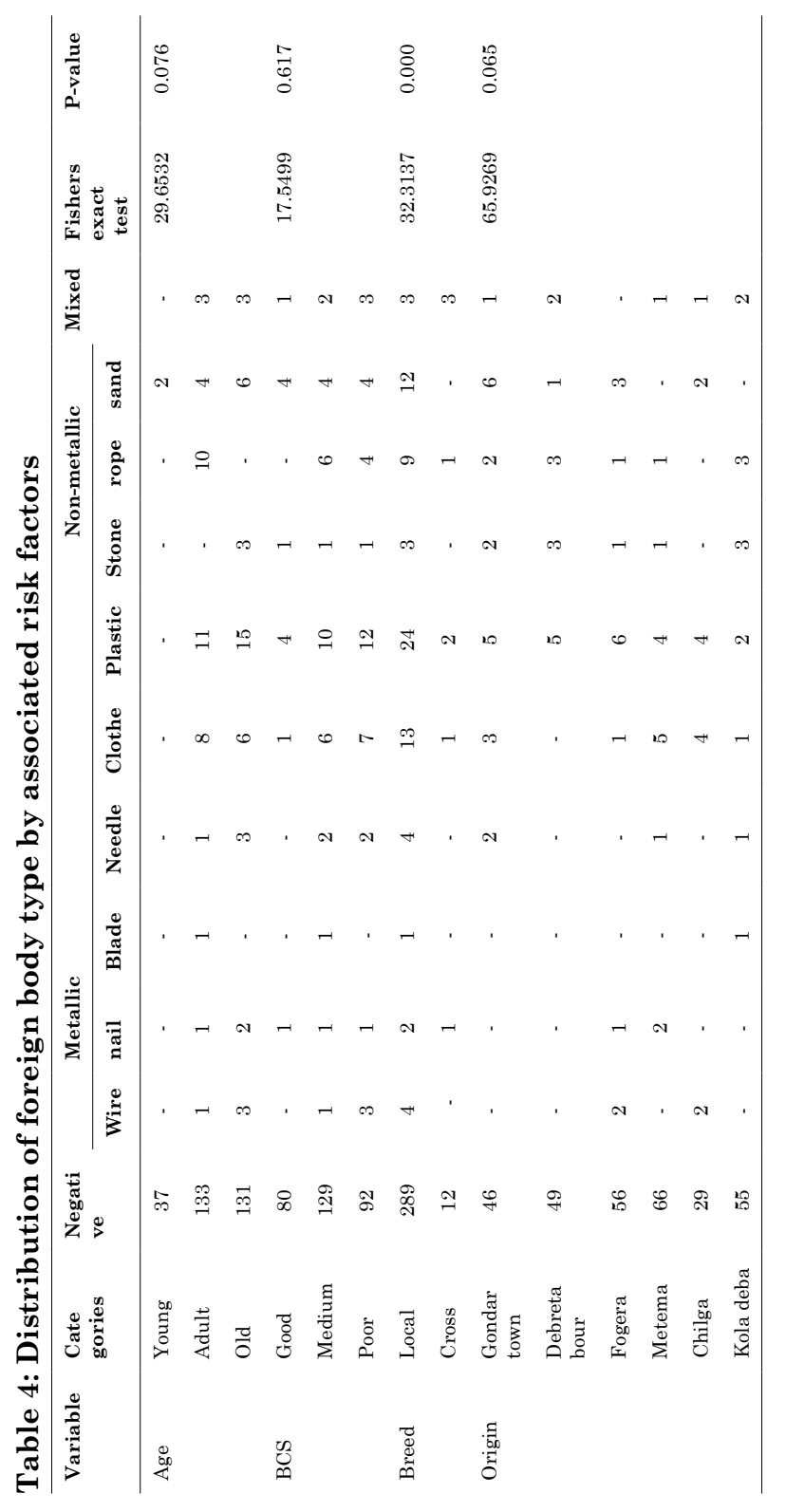




\section{Discussion}

Fore-stomach foreign body is an important potential health problem in Gondar area. The finding of the present study demonstrated that one in fifth $(21.61 \%$, 83/384) examined cattle were affected in the study area. This finding concurs with the findings of Tesfaye et al (2012) who reported 23.9\% from Hirna municipal abattoir and 23.4\% published from Addis Ababa municipality abattoir by Tiruneh and Yesuwork (2010). It was slightly higher than the reports of Rahel (2011), Kassahun et al. (2015), Tesfaye and Chanie (2012), who reported 17.07\% in Hawassa Municipal Abattoir, $14.8 \%$ in Gondar ELFORA abattoir and $13.22 \%$ in Jimma Municipal Abattoir, respectively. In the contrary, Ismael et al. (2007) reported higher overall prevalence of foreign body (77.41\%) in Jordan. The variation could be due to differences in the waste management systems in different study areas, sex of animals and season which study was conducted. Moreover, it might be due to indiscriminate feeding habit of cattle.

The higher prevalence rate was found in older animals $(23.84 \%)$ than adult and young animals. This finding is close to the reported $25.6 \%$ prevalence in older animals by Kassahun et al (2015). But it is lower than the results of Tesfaye and Chanie (2012), Rahel (2011), Radostitis et al. (2007) and Ismael et al. (2007) who reported $81.25 \%, 63.3 \%, 56.6 \%$ and $32.25 \%$ in older animals respectively. This might be associated with extended time of exposure which increases with the age of the animal and positivity of chronically affected animals.

Poor body conditioned animals were more affected than medium and good body conditioned animals. The present finding was in agreement with Tesfaye et al. (2012) who reported $26 \%$, lower than the results of Tesfaye and Chanie (2012) who reported $72.72 \%$ and was higher than the findings of Rahel (2011) who reported $15 \%$ in poor body conditioned animals. Poor body condition by itself might be due to the contribution of the foreign body, or it might be due to the interference of the foreign body with the absorption of volatile fatty acid and thus causes reduced weight gain.

Our study demonstrated that forestomach foreign body prevalence was higher in crossbreed animals (40.0\%) than local breeds (20.5\%). The result is in agreement with Tesfaye and Chanie (2012) as 70\%, Nugusu et al. (2013) as $62.2 \%$ and Rahel (2011), who reported $58.82 \%$ prevalence of forestomach foreign body in crossbreeds. This might be associated with body size and higher productiv- 
ity which requires high demand of nutrition and hence increase exposure for foreign bodies.

Animals originated from Kolladeba were 2.78 times more likely to have risk of acquiring foreign body than animals originated from Gondar town. This might be due to animals in Gondar town are reared in small feedlots that restrict their movement, whereas, in Kolladeba most of the farmers practiced free grazing. From the positive cases $(\mathrm{N}=83)$, higher proportion of fore stomach foreign body is recovered from rumen (49.40\%) and zero from omasum. This finding is higher than the findings of Bassa and Tesfaye (2017) who reported $10.83 \%$ in rumen at Wolaita Sodo municipal Abattoir and lower than the reports of Ushula and Nana (2017) in the rumen at Hawassa municipal abattoir (87\%). This might be associated with the larger rumen volume, the cumulative size and material composition of the foreign bodies and the types of materials, with metals and sharp objects tending to localize preferentially in reticulum (Radostits, 2007). Besides, the present study revealed zero prevalence from omasum which might be associated with the anatomical position of omasum and structure of reticulo-omasal orifices which is elevated above the floor to retain heavy object in the reticulum and the material that can pass omasal compartment is very small in size (less than $1.2 \mathrm{~mm}$ ). Hence, such size of material was not possible to visualized with naked eye.

The types of foreign bodies detected were plastics, cloths, sands, ropes, needles, wires, nails, stones, blades and mixed. From those, the most frequently observed fore-stomach foreign bodies in cattle slaughtered at Gondar ELFORA abattoir were plastics 26 (31.33\%). This finding agreed with various reports from different areas of Ethiopia 21(41.2\%) by Kassahun et al., 2015 and 22(44.89\%) by Tesfaye and Chanie (2012). The highest prevalence of plastics might be due to lack of good waste management, lack of awareness in the society about the side effect of plastic material in livestock production and improper disposal of plastics.

\section{Conclusion}

The present study revealed an overall prevalence of $21.61 \%$ fore-stomach foreign body in cattle in the study area. Adult and old animals were 4.33 and 4.54 times more likely to have a chance of getting foreign body than young animals, respectively. Rumen harbored more foreign bodies (49.40\%) than other compartments of the fore-stomach. Therefore, proper waste management, an 
adequate mineral supplement for animals and increasing awareness about the side-effects of plastics should be considered in the study area.

\section{Declaration of conflict of interest}

Authors declare, there is no conflicts interest.

\section{Acknowledgment}

Thanks to Gondar ELFORA abattoir for their unreserved support and voluntariness to perform this study.

\section{References}

Bassa, K., Tesfaye, W., 2017. Study on rumen and reticulum foreign bodies in cattle slaughtered at Wolaita Sodo municipal Abattoir, Ethiopia. Int. J. Adv. Multidiscip. Res., 4(1), 11-19.

CSA (Central Statistical Authority), 2015: Agricultural sample Survey 2014/15.

De-Lahunta, A., and Habel, R., 1986. Teeth Applied Veterinary Anatomy. Webester Saunder Company, UK. Pp. 4-6.

FAO, 2015. World Cattle Inventory: Ranking of countries, Food and Agricultural Organization (FAO), Rome, Italy.

Food and Agricultural Organization (FAO), 2009. Good Practices for the Meat Industry. Rome, Italy.

Ismael, Z., AI-Majali, A., and AI-Qudah. K., 2007. Clinical and surgical findings and outcome following rumenotomy in adult dairy cattle affected with recurrent rumen tympany associated with non-metallic foreign bodies. Amer. J. of Anim. and Veter. Sci. 2(3), 66-71.

Jemberu, A., Wube, A., Hirpa, A., Yehualaw, B., Asnake, A. and Kumar, N., 2018. Prevalence of Indigestible Foreign Bodies in Rumen and Reticulum in Cattle. Acad. J. of Anim. Dise., 7(2), 39-48

Kassahun, B., Erkihun, T., Berihun, M., and Bewuketu, A., 2015. Study on Rumen and Reticulum Foreign Body in Slaughtered Cattle at Gondar ELFORA Abattoir. W. J. of Bio. and Med. Sci, 2(4), 133-150.

Nicholson, M., and Butterworth, M., 1986. A guide to condition scoring of zebu cattle. International Livestock Center for Africa, Addis Ababa, Ethiopia. Pp: 1- 29. 
Nugusu, S., Velappagounder, R., Unakal, C., and Raja, N., 2013. Studies on foreign body ingestion and their related complications in ruminants associated with inappropriate Solid Waste Disposal in Gondar Town, North West Ethiopia. Int. J. Anim. and Vet. Adv. 5(2), 67-74.

Pace, J., and Wakeman, D., 2003. Determining the age of cattle by their teeth. CIR 253 Department of Animal Science, Cooperative Extension Service, Institute of Food and Agricultural Sciences, University of Florida, Gainesville. USA. Pp: 1-4.

Radostits, O., Blood, C., Hinchclif, K., and Constable, P., 2007. Veterinary medicine: a text book of disease of cattle, horse, sheep, pig and goat. $10^{\text {th }}$ ed, Saunders, London, UK. Pp. 112-522.

Rahel, M., 2011. Study on fore stomach foreign body in cattle slaughtered at Hawassa Municipal Abattoir, Ethiopia, DVM thesis, Gondar University, Faculty of Veterinary Medicine, Gondar, Ethiopia.

Ramaswamy, V., and Sharama, H. R., 2011. Plastic bags treat to environmental and cattle health. A retro perspective study from Gondar city of Ethiopia. The IOAB J. Special Issue on Environmental Management for Sustainable Development, 2 (1), 7-12.

Sharma, M., and Pankaj, K., 2006. Foreign Body Syndrome in Buffaloes (Bubalus bubalis): An Emerging Threat. Asia, J. of Anim. Vet. Adv., 1, 89-98.

Tesfaye, D., Daba, D., Mekibib, B., and Fekadu, A., 2012. The Problem of Environmental Pollution as Reflected in the Fore Stomach of Cattle: A Postmortem Study in Eastern Ethiopia. G. J. of Env. Res., 6 (2), 61-65.

Tesfaye, D., and Chanie, M.,2012. Study on Rumen and Reticulum Foreign Bodies in Cattle Slaughtered at Jimma Municipal Abattoir, South West Ethiopia. Amer. Eur. J. of Sci. Res. 7(4), 160-167.

Thrusfield, M., 2005. Veterinary Epidemiology, $3^{\text {rd }}$ ed. Blackwell publishing Ltd, Oxford, UK. Pp. 233-250.

Tiruneh, R., and Yesuwork, H., 2010. Occurrence of rumen foreign bodies in sheep and goats slaughtered at the Addis Ababa Municipality Abattoir, Ethiop. Vet. J., 14(1), 91-100.

Vanitha, V., Nambi, A., Gowri, B., and Kavitha, S., 2010. Rumen impaction in cattle with indigestible foreign bodies. Vet. and Anim. Sci. 6, 138-140.

WARDO (Woreda Agricultural and Rural Development Office), 2012. Gondar Zuria, Agricultural Censes Report. 